\title{
HIP FRACTURE IN A DEVELOPING COUNTRY: A PICTURE IN NEED OF CHANGE
}

\author{
E.I.O. Vidal ${ }^{1}$, D.C. Moreira-Filho' ${ }^{2}$ R.S. Pinheiro ${ }^{3}$, R.C. Souza $a^{4}$, L.M. Almeida ${ }^{5}$, K.R. Camargo Jr ${ }^{6}$, \\ P.J.F. Villas Boas ${ }^{1}$, F.B. Fukushima, C.M. Coeli ${ }^{3}$
}

\begin{abstract}
Objectives: To describe the clinical profile, patterns of care and mortality rates of aged patients who have undergone hip fracture surgical repair. Design: Retrospective patient record study. Setting: A public university hospital in Rio de Janeiro, Brazil. Participants: 352 patients aged 60 and older who underwent surgery for hip fracture between 1995-2000. Measurements: Sociodemographic data, type of fracture, cause of fracture, time from fracture to surgery, physical status, Charlson comorbidity index, type of surgery and anesthesia, access to in-hospital physiotherapy, use of antibiotic and thromboembolism prophylaxis, and mortality within one year after hospital admission. Results: Among 352 subjects, $74.4 \%$ were women. The mean age overall was 77.3 years. Very long delays from the time of fracture to hospital admission (mean 3 days) and from hospital admission to surgery (mean 13 days) were observed. Most femoral neck fractures $(82.7 \%$ ) were managed by hip arthroplasties, while $92.8 \%$ of the intertrochanteric fractures underwent internal fixation procedures. Less than $10 \%$ of patients received in-hospital physiotherapy. Mortality rates 30 days, 90 days and one year after hospital admission were $3.4 \%, 8.0 \%$ and $13.4 \%$, respectively. Conclusion: Our study provides evidence within the context of a developing country of major gaps in the quality of care of vulnerable older adults who suffered a hip fracture. Our findings suggest that hip fracture has not been treated as an urgent condition or a priority within the Brazilian public healthcare system. Further research should address current patterns of care for hip fracture in Brazil and in other developing countries.
\end{abstract}

Key words: Hip fractures, osteoporosis, quality of health care, developing countries, Brazil.

\section{Introduction}

Hip fracture represents the most severe consequence of osteoporosis and a major cause of morbidity, institutionalization and mortality for older adults worldwide (1-4). Around the Globe there is great variability concerning the incidence of hip fracture and its related mortality (5-8). Even though the greatest increase in the incidence of hip fracture is expected to occur in the developing countries of the world, those are also the regions from where less information is available on the epidemiology of those fractures $(6,8)$. There is particularly few data concerning Latin American older adults with hip fracture (8-11). More data on the

1. Geriatrics Division - Internal Medicine Department - Universidade Estadual Paulista (UNESP); 2. Preventive and Social Medicine Department - Universidade Estadual de Campinas (UNICAMP); 3. Instituto de Estudos em Saúde Coletiva (IESC) - Universidade Federal do Rio de Janeiro (UFRJ); 4. Faculdade de Ciencias Medicas - Universidade Estadual do Rio de Janeiro (UERJ); 5. Epidemiology Division - Instituto Nacional do Câncer (INCA); 6. Social Medicine Institute Universidade Estadual do Rio de Janeiro (UERJ); 7. Anesthesiology Department Universidade Estadual Paulista (UNESP)

Corresponding Author: Edison Iglesias de Oliveira Vidal, Departamento de Clínica Médica, Faculdade de Medicina de Botucatu - UNESP, 18618-970 , Botucatu - SP Brazil, E-mail: eiovidal@fmb.unesp.br epidemiology of those fractures is fundamental for the design of age-friendly public policies in those countries, where population aging is a relatively new phenomenon. Therefore, we conducted a study to describe the clinical profile, the patterns of care, and mortality rates of individuals aged 60 and older who underwent surgical repair of a hip fracture at a public university hospital in the city of Rio de Janeiro, Brazil.

\section{Methods}

The medical records of all patients aged 60 years and older admitted with a primary diagnosis of hip fracture (first three digits of International Classification of Diseases, 9th revision, ICD-9, code 820) between January 1st, 1995 and December 31st, 2000 were retrospectively reviewed. Patients with pathological hip fracture related to malignancy or who did not undergo surgical repair were excluded.

Review of medical records was performed using a standardized data abstraction form, which was completed by trained medical students under the supervision of a senior medical researcher (LMA). Before 
being used for this research the abstraction form was pretested with a sample of medical charts and corrections were implemented in order to facilitate the abstraction process and minimize bias. The medical supervisor reviewed all data for inconsistencies and medical records were reappraised accordingly. The same professional was responsible for the insertion of all data into the database.

To assess mortality rates within one year after hospital admission, records were linked to the database of the Brazilian Mortality Information System from January 1st, 1995 to December 31st, 2001 using Probabilistic Record Linkage Methodology $(9,12-16)$. Previous research in a similar setting revealed $85.5 \%$ sensitivity, $99.4 \%$ specificity, $98.1 \%$ positive predictive value and $94.9 \%$ negative predictive value for correct matching of records between databases using this methodology (17). RecLink II Software (18) was used to implement the Probabilistic Record Linkage Methodology followed by manual examination of pairs of records with higher probability of representing a true match between databases.

Frequency tables were created for the following variables: sex, age, income strata, marital status, living arrangements, type of hip fracture, type of injury leading to the fracture, type of surgical treatment and anesthesia, prophylaxis against venous thromboembolism and surgical infections (i.e. prophylactic antibiotic regimens), access to in-hospital physiotherapy care, comorbidities as ascertained by the Charlson comorbidity index (19), and American Society of Anesthesiology (ASA) physical status score. Statistical analyses were restricted to the presentation of simple frequencies and the calculation of 95\% confidence intervals according to standard methods (20). The R software (version 2.10.1) was used for such purposes (21).

The present research was approved by the ethics committee of the Public Health Studies Institute of the Universidade Federal do Rio de Janeiro. Because of the retrospective nature of the study involving patients' medical records and anonymous treatment of data, the ethics committee waived the requirement for informed consent.

\section{Results}

Figure 1 shows the flow diagram of the inclusion of patients in the study. Among the 352 patients fulfilling the proposed inclusion criteria, there were $262(74.4 \%)$ women. The mean age overall was 77.3 years and women were mean 3.7 years older than men (mean ages 78.2 and 74.5 years, respectively; $\mathrm{P}=0.001$ ). The mean and median lengths of hospital stay were 21 and 17 days, respectively, with an interquartile range of 14 to 24 days. The mean and median times from the occurrence of hip fracture to hospital admission were 3 and 1 days, respectively, with an interquartile range of 0 to 4 days. The mean and median times from hospital admission to surgery were 13 and 11 days, respectively, with an interquartile range of 8 to 17 days. Figure 2 shows the distribution of time from hospital admission to surgery. Table 1 depicts the sociodemographic characteristics of the patients. Table 2 shows the clinical profile of patients including number of comorbidities, types and causes of hip fracture, Charlson comorbidity index and ASA physical status score. Table 3 displays the frequencies of surgical and anesthetic approaches adopted, as well as the frequencies of inhospital physiotherapy, antibiotic and thromboembolism prophylaxis. Most femoral neck fractures $(82.7 \%)$ were managed by hip arthroplasties, while $92.8 \%$ of the intertrochanteric fractures and $96.2 \%$ of the subtrochanteric fractures underwent internal fixation procedures. In-hospital mortality was $5.4 \%$. Mortality rates 30 days, 90 days and one year after hospital admission were $3.4 \%, 8.0 \%$ and $13.4 \%$, respectively.

Figure 1

Flow diagram of inclusion of patients in the study

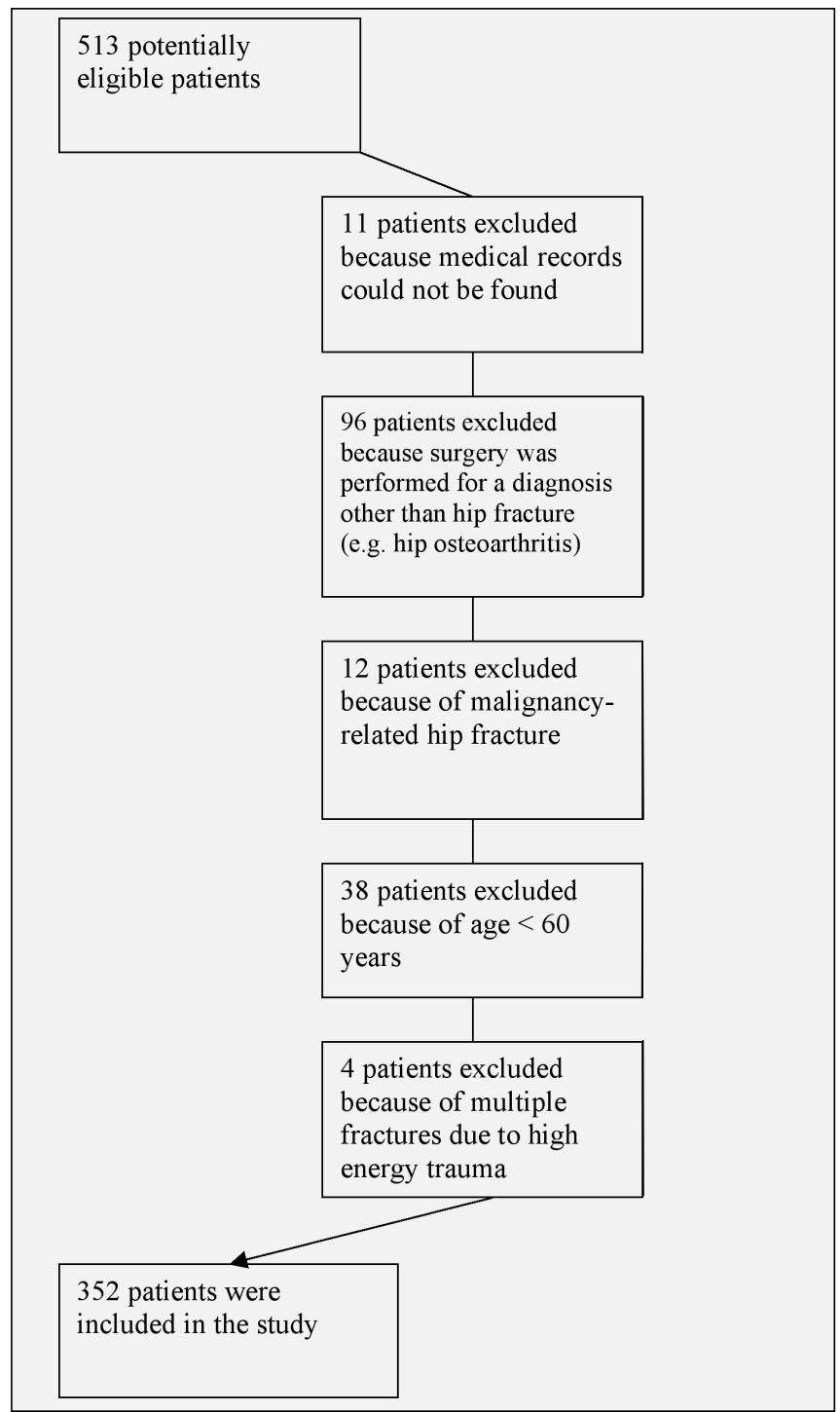


Table 1

Sociodemographic characteristics of patients

\begin{tabular}{lccc}
\hline & $\mathbf{N}$ & $\%$ & $\mathbf{9 5 \%} \mathbf{C I}$ \\
\hline Gender & & & $69.47-78.84$ \\
Female & 262 & 74.43 & $21.15-30.52$ \\
Male & 90 & 25.57 & $19.31-28.43$ \\
Age & & & $25.96-35.83$ \\
60 to 69 & 83 & 23.58 & $33.29-43.69$ \\
70 to 79 & 108 & 30.68 & $4.97-10.77$ \\
80 to 89 & 135 & 38.35 & \\
90 or + & 26 & 7.39 & $9.57-16.84$ \\
Marital Status & & & $29.47-39.63$ \\
Single & 45 & 12.78 & $0.36-3.08$ \\
Married or in stable partnership & 121 & 34.38 & $41.03-51.67$ \\
Divorced & 4 & 1.14 & $3.37-8.45$ \\
Widowed & 163 & 46.31 & $44.10-54.77$ \\
Unspecified & 19 & 5.40 & $11.57-19.32$ \\
Income strata* & & & $0.36-3.08$ \\
Low income & 174 & 49.43 & $29.47-39.62$ \\
Middle income & 53 & 15.06 & $7.36-13.99$ \\
High income & 4 & 1.14 & $63.58-73.50$ \\
Unspecified & 121 & 34.38 & $16.96-25.73$ \\
Living arrangement & & & \\
Lives alone & 36 & 10.23 & 68.75 \\
Lives with partner or other people & 242 & 21.02 & \\
Unspecified & 74 & & \\
\hline
\end{tabular}

* Income strata: Household income was classified as low income ( $\leq 5$ minimum wages), middle income (6-20 minimum wages), and high income ( $>20$ minimum wages). The minimum wage is defined by law in Brazil and corresponds to the lowest value employers may legally pay to workers for a month of work."

Figure 2

Histogram of the interval of time* from hospital admission to surgery for 352 patients who underwent surgical repair of a hip fracture between 1995-2000

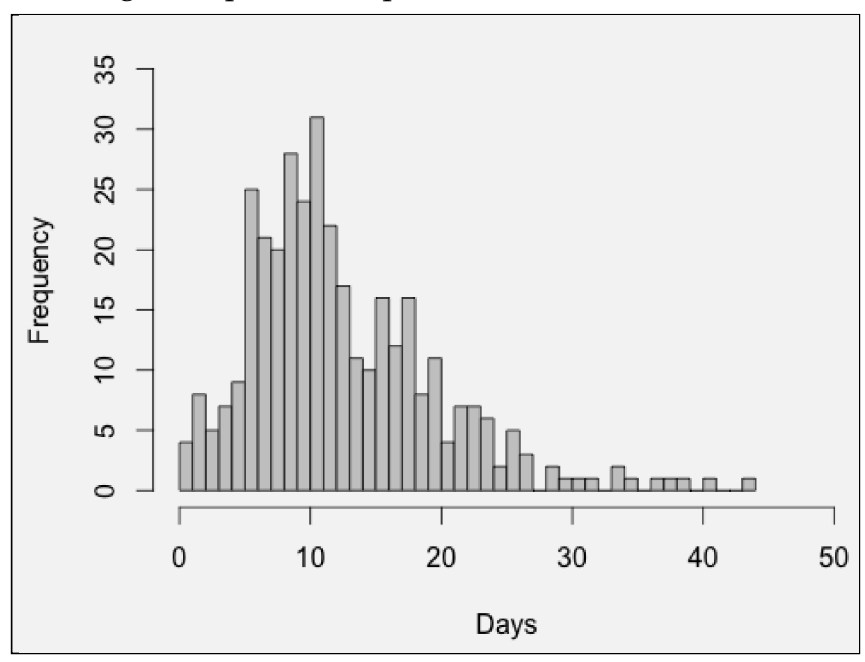

* The data plotted in the histogram is "left-closed" and "right-open" (i.e. the column between day 0 and day 1 represents the number of patients who were operated on the same day of hospital admission, i.e. day 0; whereas the column between 1 and 2 represents the number of patients who were operated one day after hospital admission, i.e. day 1).

\section{Discussion}

Probably, the most striking finding of the current research was the occurrence of mean intervals of time from fracture to hospital admission and thereafter to surgery of 3 and 13 days, respectively. Those intervals of time from fracture to surgery are remarkably different from those reported in developed countries, where the vast majority of patients undergo surgery within the first $48 \mathrm{~h}$ of hospital admission (22-27). Even though there is still some degree of debate over the association between surgical timing and patient mortality after a hip fracture $(25,28,29)$, there is wide consensus in the literature that hip fracture patients should be operated on as early as possible after hospital admission, provided there are no conditions that can be corrected or improved prior to surgery, since long waiting times for surgery are associated with pain, pressure ulcers, long hospital stays, distress, and delayed mobilization (23, 25, 27-30). We have recently shown for the same context of care that those long delays from fracture to hospital admission are associated with increased mortality risk (31).

Less than $10 \%$ of patients received in-hospital physiotherapy care, which is significantly divergent from current recommendations for early mobilization for most patients following the surgical repair of a hip fracture (32, 33). Such a low frequency of in-hospital physiotherapy care also mirrors important limitations in the access to 
Table 2

Clinical profile of patients

\begin{tabular}{|c|c|c|c|}
\hline & $\mathbf{N}$ & $\%$ & $95 \% \mathrm{CI}$ \\
\hline \multicolumn{4}{|l|}{ Type of fracture } \\
\hline Femoral neck & 133 & 37.78 & $32.74-43.10$ \\
\hline Intertrochanteric & 193 & 54.83 & $49.46-60.09$ \\
\hline Subtrochanteric & 26 & 7.39 & $4.97-10.77$ \\
\hline \multicolumn{4}{|l|}{ Cause of the fracture } \\
\hline Fall & 313 & 88.92 & $85.05-91.91$ \\
\hline High intensity trauma & 19 & 5.40 & $3.37-8.44$ \\
\hline Other & 10 & 2.84 & $1.45-5.33$ \\
\hline Unspecified & 10 & 2.84 & $1.45-5.33$ \\
\hline \multicolumn{4}{|l|}{ Physical Status $\left(A S A^{*}\right)$} \\
\hline ASA I (Normal healthy patient) & 12 & 3.41 & $1.86-6.04$ \\
\hline ASA II (Mild systemic disease) & 185 & 52.56 & $47.20-57.86$ \\
\hline ASA III (Severe systemic disease) & 125 & 35.51 & $30.56-40.79$ \\
\hline ASA IV (Severe systemic disease / constant threat to life) & 7 & 1.99 & $0.87-4.23$ \\
\hline Unspecified & 23 & 6.53 & $4.28-9.78$ \\
\hline \multicolumn{4}{|l|}{ Charlson Comorbitity Indext } \\
\hline 0 & 199 & 56.53 & $51.12-61.75$ \\
\hline 1 & 126 & 35.80 & $30.83-41.08$ \\
\hline 2 & 25 & 7.10 & $4.74-10.44$ \\
\hline 3 & 2 & 0.57 & $0.10-2.26$ \\
\hline \multicolumn{4}{|l|}{ Number of comorbidities } \\
\hline 0 & 55 & 15.63 & $12.09-19.94$ \\
\hline 1 & 92 & 26.14 & 21.69-31.11 \\
\hline 2 & 96 & 27.27 & $22.75-32.30$ \\
\hline 3 & 54 & 15.34 & $11.83-19.63$ \\
\hline 4 or + & 55 & 15.63 & $12.09-19.94$ \\
\hline
\end{tabular}

* ASA: American Society of Anesthesiology Physical Status Classification; + Charlson Comorbidity Index: increasing scores mean growing burden of comorbidities

Table 3

Treatment patterns

\begin{tabular}{|c|c|c|c|}
\hline & $\mathbf{N}$ & $\%$ & $95 \% \mathrm{CI}$ \\
\hline \multicolumn{4}{|l|}{ Type of surgery } \\
\hline Internal fixation & 225 & 63.92 & $58.63-68.90$ \\
\hline Hip arthroplasty & 124 & 35.23 & $30.29-40.50$ \\
\hline Other & 3 & 0.85 & $0.22-2.68$ \\
\hline \multicolumn{4}{|l|}{ Type of anaesthesia } \\
\hline General anaesthesia & 52 & 14.77 & 11.32-19.01 \\
\hline Neuroaxial anaesthesia & 261 & 74.14 & $69.18-78.58$ \\
\hline Combination of general + neuroaxial anaesthesia & 33 & 9.38 & $6.63-13.03$ \\
\hline Unspecified & 6 & 1.70 & $0.69-0.39$ \\
\hline \multicolumn{4}{|l|}{ Clinical procedures } \\
\hline Thromboembolism prophylaxis & 334 & 94.89 & $91.89-96.85$ \\
\hline Antibiotic prophylaxis & 332 & 94.32 & $91.22-96.41$ \\
\hline Physiotherapy during hospital stay & 31 & 8.81 & $6.15-12.39$ \\
\hline
\end{tabular}

optimal healthcare resources by older adults, since functional recovery after hip fracture is highly dependent on early rehabilitation after surgery (34). Nevertheless, almost $95 \%$ of patients received thromboembolism and antibiotic prophylaxis, which are significantly easier interventions to implement within any institution than the organization of post-surgical rehabilitation resources.
The current observations of long delays to hospital admission and to surgery above the standard of care in developed countries (i.e. surgery within $48 \mathrm{~h}$ of hospital admission), and the remarkably low frequency of inhospital physiotherapy care indicate that, even though hip fracture is associated with lower survival rates than that of most invasive cancers pooled together (35), it has 
not been treated as an urgent condition or a public health priority in Brazil. Because there is evidence that injuries and surgical conditions represent a problematic and neglected aspect of healthcare in developing countries we believe that similar and even worse patterns of care are likely in other developing regions of the World (36-40). This perspective is alarming since those fractures represent an enormous burden for society and because the greatest increase in the incidence of hip fracture is predicted to take place in the developing countries of the world $(6,8)$.

We hypothesize that those findings might reflect a picture of ageism within the Brazilian healthcare system $(41,42)$, where older adults have less access to more costly procedures within the public healthcare system than younger individuals, as has been shown by others (43). We hypothesize several other reasons that could explain the findings of delayed surgical timing and low physiotherapy frequency within our study. First, surgical procedures for hip fracture may have been scheduled as elective instead of urgent procedures, and therefore occurred according to operating theater availability, without prioritizing those vulnerable patients. Second, it is possible that in Brazil the lay public and even many healthcare professionals are frequently unaware of the often life-threatening meaning of a hip fracture for older people. Those hypotheses warrant further investigation by future studies. Although universal access to public health care in Brazil has been legally established since 1988, patients still often suffer from suboptimal care in several areas of healthcare provision (44). While the population is aging rapidly, the public healthcare system is still struggling to recognize and adapt to the needs of older people (45).

High rates of arthroplasty procedures for femoral neck fractures were observed. This finding is probably related to the large intervals of time from fracture to surgery, since those delays are associated with increased risk of fracture displacement and avascular necrosis of the head of the femur, and therefore represent a clear indication for hip arthroplasty (46).

The majority of patients $(74.1 \%)$ underwent neuroaxial anesthesia (i.e. spinal or epidural), which represents a somewhat different pattern than that observed in many other regions of the Globe where general anesthesia usually represents a larger share of the anesthetic procedures performed for hip fracture patients (47-49). The debate over what type of anesthetic procedure is best suited for hip fracture patients does not seem to be resolved. Notwithstanding, recent systematic reviews disclosed lower mortality 30 days after surgery, lower incidence of deep venous thrombosis and lower rates of postoperative mental confusion for hip fracture patients who underwent neuroaxial anesthesia than for those submitted to general anesthesia $(49,50)$.

The one-year mortality rate observed $(13.4 \%)$ was much lower than the $21.5 \%$ mortality rate described previously in a study encompassing all public hospitals in the city of Rio de Janeiro (9) and lies in the lower limits of mortality reported for hip fracture around the world $(1,2)$. The finding of low patient mortality concomitant to markers of suboptimal patient care discussed in the previous paragraphs may seem paradoxical at first. However, this apparent paradox can be explained by several factors, as follows. First, University hospitals have been shown to be associated with lower mortality rates for hip fracture than general hospitals, even though they often display longer intervals of time from hospital admission to surgery than community hospitals (24). Second and most important, selection bias must be strongly considered as a reason for the discrepancy between inadequate patterns of care and low mortality rates. Frailer and sicker patients, who had been admitted with a hip fracture to a community hospital without hip fracture surgical capability, were likely not considered fit to be transferred to the university hospital under study or died before they could be transferred, hence creating selection bias. Two observations are consistent with this last hypothesis: (a) most patients in this study were attributed a low Charlson comorbidity index and only roughly one third of patients were considered to have a severe systemic disease as ascertained by the ASA physical status classification; (b) the patient population was relatively younger than usually reported by most studies from developed countries $(24,51,52)$.

At least $49.4 \%$ of patients in our study belonged to a low socioeconomic stratum. About $60 \%$ of patients were widowed, divorced or single. As usual in epidemiological studies about hip fracture among older adults, most patients $(74.4 \%)$ were women. Even though the relationship between socioeconomic status and risk of falls is debated (53), there is evidence that lower socioeconomic status is associated not only with increased incidence of hip fracture (54-57) but also with increased mortality after fracture (58). Divorced, widowed and unmarried status have also been reported by others to be associated with increased risk of hip fracture $(56,59)$. The association between low socioeconomic status and increased risk of hip fracture may be related to several factors ranging from decreased bone mineral density and underlying health behaviors to environmental influences (55).

Several limitations of this study must be considered. Since its design was based on the retrospective abstraction of medical records, we had limited or no access to some data on important aspects of patients' baseline characteristics and outcomes, such as socioeconomic status and functional outcomes. Second, review of medical records is often associated with error and bias, which can never be completely discarded in studies like ours. Nevertheless, most of the data that we collected for this analysis was relatively straightforward 
(e.g. date of hospital admission, date of surgery and record of occurrence of in-hospital physiotherapy care) and an experienced medical supervisor worked in close contact with the chart reviewers in order to attempt to minimize bias. In addition, other researchers have conducted valuable studies about the epidemiology of hip fractures using similar methods $(60,61)$. Third, limitations in methodology mean that the present results are not generalizable to the whole city of Rio de Janeiro or to other regions of the country. It is nevertheless reasonable to presume that the current findings have significant similarities to the patterns of care in other public hospitals in the same region, which are part of the same public healthcare system. Fourth, our results are at least 10 years old and a note of caution should be added to their generalizability to current practice. However, more recent studies about hip fracture among older adults from other regions of Brazil also showed long surgical delays, which suggests that the substandard patterns of care we have reported might still be common and may require urgent public health attention $(62,63)$.

\section{Conclusions}

Our study provides evidence within the context of a developing country of major gaps in the quality of care of vulnerable older adults who sustained a hip fracture between 1995 and 2000. Those findings suggest that hip fracture has not been treated as an urgent condition or a priority within the Brazilian public healthcare system. Further research should address the current patterns of care for hip fracture in the elderly both in Brazil and in other developing countries. Since our findings have been at least in part replicated by more recent studies conducted in other regions of our country, we believe that urgent public health attention is warranted towards the care of older adults sustaining a hip fracture in Brazil.

Competing interests: The authors declare that they have no competing interests.

Acknowledgements: This work was supported by the Brazilian National Council for Scientific and Technological Development (CNPq) [474845/2001-0]. The funding source did not play any role with respect to design, execution, data analysis and interpretation, or writing of the study.

\section{References}

1. Cummings SR, Melton LJ. Epidemiology and outcomes of osteoporotic fractures. Lancet 2002;359(9319):1761-7

2. Johnell O, Kanis J. An estimate of the worldwide prevalence, mortality and disability associated with hip fracture. Osteoporos Int 2004;15:897-902

3. Johnell $\mathrm{O}$. The socioeconomic burden of fractures: today and in the 21st century. Am J Med 1997;103(2A):20S-25S; discussion 25S-26S

4. Fisher AA, Davis MW, Rubenach SE, Sivakumaran S, Smith PN, Budge MM. Outcomes for older patients with hip fractures: the impact of orthopedic and geriatric medicine cocare. J Orthop Trauma 2006;20(3):172-178; discussion 179-180

5. Schwartz AV, Kelsey JL, Maggi S, et al. International variation in the incidence of hip fractures: cross-national project on osteoporosis for the World Health Organization Program for Research on Aging. Osteoporos Int 1999:9(3):242-53

6. Gullberg B, Johnell O, Kanis JA. World-wide projections for hip fracture.
Osteoporos Int 1997;7(5):407-13

7. Cheng SY, Levy AR, Lefaivre KA, Guy P, Kuramoto L, Sobolev B (2011) Geographic trends in incidence of hip fractures: a comprehensive literature review. Osteoporos Int 2011;22(10):2575-2586

8. Cooper C, Cole ZA, Holroyd CR, Earl SC, Harvey NC, Dennison EM, Melton LJ, Cummings SR, Kanis JA . Secular trends in the incidence of hip and other osteoporotic fractures. Osteoporos Int 2011;22(5):1277-1288

9. Vidal EI, Coeli CM, Pinheiro RS, Camargo KR. Mortality within 1 year after hip fracture surgical repair in the elderly according to postoperative period: a probabilistic record linkage study in Brazil. Osteoporos Int 2006;17(10):1569-1576

10. Pinheiro MM, Ciconelli RM, Martini LA, Ferraz MB. Clinical risk factors for osteoporotic fractures in Brazilian women and men: the Brazilian Osteoporosis Study (BRAZOS). Osteoporos Int 2009;20(3):399-408

11. Morales-Torres J, Gutierrez-Urena S. The burden of osteoporosis in Latin America. Osteoporos Int 2004;15(8):625-32

12. West of Scotland Coronary Prevention Study Group. Computerised record linkage: compared with traditional patient follow-up methods in clinical trials and illustrated in a prospective epidemiological study. J Clin Epidemiol 1995;48(12):1441-52

13. Jaro M. Probabilistic linkage of large public health data files. Stat Med 1995;14(5-7):491-498

14. Machado JP, Silveira DP, Santos IS, Piovesan MF, Albuquerque C. [The use of a probabilistic record linkage methodology in databases to identify death records in epidemiological studies]. Rev Bras Epidemiol 2008;11(1):43-54

15. Coeli CM, Camargo Jr. KR. [Evaluation of different blocking strategies in probabilistic record linkage]. Rev Bras Epidemiol 2002;5(2):185-196

16. Shannon HS, Jamieson E, Walsh C, Julian JA, Fair ME, Buffet A. Comparison of individual follow-up and computerized record linkage using the Canadian Mortality Data Base. Can J Public Health 1989;80(1):54-7

17. Coutinho ES, Coeli CM. [Accuracy of the probabilistic record linkage methodology to ascertain deaths in survival studies]. Cad Saude Publica 2006;22(10):2249-52

18. Camargo Jr. KR, Coeli CM. [Reclink: an application for database linkage implementing the probabilistic record linkage method]. Cad Saude Publica 2000;16(2):439-47

19. Charlson ME, Pompei P, Ales KL, MacKenzie CR. A new method of classifying prognostic comorbidity in longitudinal studies: development and validation. J Chronic Dis 1987;40(5):373-83

20. Fleiss JL, Levin BA, Paik MC. Statistical methods for rates and proportions. J. Wiley, Hoboken, N.J. 2003;

21. R Development Core Team. R: A Language and Environment for Statistical Computing. R Foundation for Statistical Computing, Vienna, Austria, 2009

22. Vidal EI, Moreira-Filho DC, Coeli CM, Camargo KR, Fukushima FB, Blais R. Hip fracture in the elderly: does counting time from fracture to surgery or from hospital admission to surgery matter when studying in-hospital mortality? Osteoporos Int 2009;20(5):723-9

23. Orosz GM, Magaziner J, Hannan EL, et al. Association of timing of surgery for hip fracture and patient outcomes. Jama 2004;291(14):1738-43

24. Weller I, Wai EK, Jaglal S, Kreder HJ. The effect of hospital type and surgical delay on mortality after surgery for hip fracture. J Bone Joint Surg Br 2005;87(3):361-366

25. Shiga T, Wajima Z, Ohe Y. Is operative delay associated with increased mortality of hip fracture patients? Systematic review, meta-analysis, and meta-regression. Can J Anaesth 2008;55(3):146-54

26. National Services Scotland. Scottish Hip Fracture Audit report 2008. 17

27. Vidan MT, Sanchez E, Gracia Y, Maranon E, Vaquero J, Serra JA. Causes and effects of surgical delay in patients with hip fracture: a cohort study. Ann Intern Med 2011;155(4):226-233

28. Kahn SK, Kalra S, Khanna A, Thiruvengada MM, Parker MJ. Timing of surgery for hip fractures: a systematic review of 52 published studies involving 291,413 patients. Injury 2009:40(7):692-697

29. Leung F, Lau TW, Kwan K, Chow SP, Kung AWC. Does timing of surgery matter in fragility hip fractures? Osteoporos Int 2010;21(Suppl 4):S529-534

30. Hung W, Morrison RS. Hip Fracture: a complex illness among complex patients. Ann Intern Med 2011;155(4):267-268

31. Vidal EIO, Moreira-Filho DC, Pinheiro RS, Souza RC, Almeida LM, Camargo KR Jr, Boas PJFV, Fukushima FB, Coeli CM. Delay from fracture to hospital admission: a new risk factor for hip fracture mortality? Osteoporos Int. 2012; doi: 10.1007 / s00198-012-1917-x

32. Scottish Intercollegiate Guidelines Network. Prevention and management of hip fracture in older people : a national clinical guideline. SIGN, Edinburgh, 2002.

33. Beaupre LA, Jones CA, Saunders LD, Johnston DW, Buckingham J, Majumdar SR. Best practices for elderly hip fracture patients. A systematic overview of the evidence. J Gen Intern Med 2005;20(11):1019-25

34. Penrod JD, Boockvar KS, Litke A, et al. Physical therapy and mobility 2 and 6 months after hip fracture. J Am Geriatr Soc 2004;52(7):1114-1120

35. Howlader N, Noone AM, Krapcho M, et al SEER Cancer Statistics Review 1975-2008. In: SEER Cancer Statistics Review, 1975-2008, National Cancer 
Institute. based on November 2010 SEER data submission, posted to the SEER web site, 2011. http:// seer.cancer.gov/csr/1975_2008/index.html. Accessed 14 Dec 2011

36. Jain AK. Orthopedic services and training at a crossroads in developing countries. Indian J Orthop 2007;41(3):177-179

37. Nwachukwu BU, Okwesili IC, Harris MB, Katz JN. Traditional Bonesetters and Contemporary Orthopaedic Fracture Care in a Developing Nation Historical Aspects, Contemporary Status and Future Directions. Open Orthop J 2011;5:20-26

38. Beveridge M, Howard A. The burden of orthopaedic disease in developing countries. The Journal of Bone \& Joint Surgery 2004;86(8):1819-1822

39. Groen RS, Samai M, Stewart K-A, Cassidy LD, Kamara TB, Yambasu SE, Kingham TP, Kushner AL. Untreated surgical conditions in Sierra Leone: a cluster randomised, cross-sectional, countrywide survey. Lancet 2012;80(9847):1082-1087

40. Shah RK, Thapa VK, Jones DHA, Jones R. Improving primary orthopaedic and trauma care in Nepal. Educ Health (Abingdon) 2003;16(3):348-356

41. Butler RN. Ageism: A Foreword. Journal of Social Issues 1980;36(2):8-11

42. Goldani AM. "Ageism" in Brazil: what is it? who does it? what to do with it? Revista Brasileira de Estudos de População 2010;27(2):385-405

43. Berenstein CK, Wajnman S. Population aging effects on inpatient care expenditures: a disaggregated analysis for two Brazilian metropolitan areas. Cadernos de Saúde Pública 2008;24(10):2301-2313

44. Ribeiro JM. SUS evolution and hospital services rationing. Ciência \&amp; Saúde Coletiva 2009;14(3):771-782

45. Lourenço RA, Martins C de SF, Sanchez MAS, Veras RP. Geriatric outpatient healthcare: hierarchical demand structuring. Revista de Saúde Pública 2005;39(2):311-318

46. Sendtner E, Renkawitz T, Kramny P, Wenzl M, Grifka J. Fractured Neck of Femur-Internal Fixation Versus Arthroplasty. Dtsch Arztebl Int 2010;107(23):401-407

47. O'Hara DA, Duff A, Berlin JA, Poses RM, Lawrence VA, Huber EC, Noveck $\mathrm{H}$, Strom BL, Carson JL. The effect of anesthetic technique on postoperative outcomes in hip fracture repair. Anesthesiology 2000;92(4):947-57

48. Dickson RE, Patey RE. Anaesthesia for hip fracture: a survey of Scottish practice. Scott Med J 1999;44(5):152-4

49. Parker MJ, Handoll HH, Griffiths R. Anaesthesia for hip fracture surgery in adults. Cochrane Database Syst Rev 2004;(4):CD000521

50. Luger TJ, Kammerlander C, Gosch M, Luger MF, Kammerlander-Knauer U, Roth T, Kreutziger J. Neuroaxial versus general anaesthesia in geriatric patients for hip fracture surgery: does it matter? Osteoporos Int 2010;21(Suppl 4):S555-572

51. Magaziner J, Fredman L, Hawkes W, Hebel JR, Zimmerman S, Orwig DL, Wehren L. Changes in functional status attributable to hip fracture: a comparison of hip fracture patients to community-dwelling aged. Am J Epidemiol 2003;157(11):1023-31

52. Nymark T, Lauritsen JM, Ovesen O, Röck ND, Jeune B. Decreasing incidence of hip fracture in the Funen County, Denmark. Acta Orthop 2006;77(1):109-113

53. Todd C, Ballinger C, Whitehead S. Reviews of sociodemographic factors related to falls and environmental interventions to prevent falls amongst older people living in the community, 2007.

54. West J, Hippisley-Cox J, Coupland CAC, Price GM, Groom LM, Kendrick D Webber E. Do rates of hospital admission for falls and hip fracture in elderly people vary by socio-economic status? Public Health 2004;118(8):576-581

55. Zingmond DS, Soohoo NF, Silverman SL. The role of socioeconomic status on hip fracture. Osteoporosis International 2006;17(10):1562-1568

56. Farahmand BY, Persson PG, Michaëlsson K, Baron JA, Parker MG, Ljunghall S. Socioeconomic status, marital status and hip fracture risk: a populationbased case-control study. Osteoporos Int 2000;11(9):803-808

57. Brennan SL, Henry MJ, Kotowicz MA, Nicholson GC, Zhang Y, Pasco JA. Incident hip fracture and social disadvantage in an Australian population aged 50 years or greater. Bone 2011;48(3):607-610

58. Quah C, Boulton C, Moran C. The influence of socioeconomic status on the incidence, outcome and mortality of fractures of the hip. J Bone Joint Surg Br 2011;93(6):801-805

59. Peel NM, McClure RJ, Hendrikz JK. Psychosocial factors associated with fallrelated hip fractures. Age and Ageing 2007;36(2):145-151

60. Juby AG, De Geus-Wenceslau CM. Evaluation of osteoporosis treatment in seniors after hip fracture. Osteoporos Int 2002;13(3):205-210

61. Jain R, Basinski A, Kreder HJ. Nonoperative treatment of hip fractures. Int Orthop 2003;27(1):11-7

62. Fortes EM, Raffaelli MP, Bracco OL, Takata ETT, Reis FB, Santili C, LazarettiCastro M. Elevada morbimortalidade e reduzida taxa de diagnóstico de osteoporose em idosos com fratura de fêmur proximal na cidade de São Paulo. Arq Bras Endocrinol Metab 2008;52(7):1106-1114

63. Gumieiro DN, Rafacho BPM, Gonçalves AF, et al. Mini Nutritional Assessment predicts gait status and mortality 6 months after hip fracture. British Journal of Nutrition 2012;1-5. 